\begin{tabular}{|c|l|}
\hline Title & Seasonal variation in membrane fouling in membrane bioreactors (MBRs) treating municipal wastewater \\
\hline Author(s) & Miyoshi, Taro; Tsuy uhara, Tomoo; Ogyu, Rie; Kimura, Katsuki; W atanabe, Y oshimasa \\
\hline Citation & $\begin{array}{l}\text { Water Research, 43(20), 5109-5118 } \\
\text { https://doi.org/40.1016j.watres.2009.08.035 }\end{array}$ \\
\hline Issue Date & 2009-12 \\
\hline Doc URL & http://hdl.handle.net/2115/42720 \\
\hline Type & article(author version) \\
\hline File Information & WR43-20_5109-5118.pdf \\
\hline
\end{tabular}

Instructions for use 


\title{
Seasonal variation in membrane fouling in membrane bioreactors (MBRs) treating municipal wastewater
}

\author{
Taro Miyoshi $^{1, *}$, Tomoo Tsuyuhara ${ }^{1}$, Rie Ogyu ${ }^{1}$, \\ Katsuki Kimura $^{1}$, Yoshimasa Watanabe ${ }^{2}$
}

1: Division of Built Environment, Hokkaido University, N13W8, Kita-ku, Sapporo

060-8628, Japan

2: Center for Environmental Nano and Bio Engineering, Hokkaido University, N13W8, Kita-ku, Sapporo 060-8628, Japan

*Corresponding author

Tel \& Fax: +81-11-706-6267

E-mail: jms-mbr@eng.hokudai.ac.jp 


\section{Abstract}

We investigated seasonal variation in membrane fouling in membrane bioreactors (MBRs) treating municipal wastewater regarding the difference between physically reversible and irreversible fouling. Two separate MBRs with different solid retention times (SRTs) operated in parallel for about 200 days including high- and low-temperature periods to evaluate the effect of operating conditions on seasonal variation of membrane fouling. Seasonal variations of both types of membrane fouling (i.e., physically reversible and irreversible fouling) were observed for the MBR with short SRT (13 days). However, in the MBR with long SRT (50 days), there were no significant seasonal variations in both types of membrane fouling. In the MBR with short SRT, the trends in the seasonal variation in the development rates of physically reversible and irreversible fouling were different. Physically reversible fouling was more significant in the low-temperature period, while physically irreversible fouling developed more rapidly in the high-temperature period. The development rates of physically reversible fouling can be related to the concentration of dissolved organic matter in the mixed liquor suspension of MBRs; whereas those of physically irreversible fouling could not be explained by the concentration of dissolved organic matter. The characteristics of dissolved organic matter differed depending on the temperature period, and the trends of dissolved organic matter variation in mixed liquor were similar with those of foulants that caused physically irreversible fouling. The results obtained in this study indicated that seasonal variation in physically reversible and irreversible fouling is related to changes in quantity and quality of organic matter, respectively.

Keywords: Membrane bioreactor, Membrane fouling, Seasonal variation 


\section{Introduction}

Membrane bioreactors (MBRs) have many advantages over conventional wastewater treatment systems including the high quality of treated water, small footprint, ease of operation, and less excess sludge, and therefore, are considered to be the leading wastewater treatment systems (Kimura et al., 2005a; Kimura et al., 2008; Stephenson et al., 2000; Yamamoto et al., 1989). For more efficient use of MBRs, however, problems associated with membrane fouling should be addressed. Membrane fouling can be divided into two categories: physically reversible fouling which can be eliminated by physical membrane cleaning such as back washing or surface cleaning, and physically irreversible fouling which cannot be eliminated by physical membrane cleaning but with chemical membrane cleaning (Chang et al., 2002). While physically reversible fouling can significantly be mitigated as long as effective physical membrane cleaning is carried out, physically irreversible fouling develops even when efficient physical membrane cleaning is applied. Therefore, control of physically irreversible fouling is also important for reducing operation cost in MBR processes. An understanding of the fouling mechanisms, including the characteristics of the constituents that cause membrane fouling in MBRs, is indispensable for controlling membrane fouling.

Soluble microbial products (SMPs) are considered as major constituents causing membrane fouling in MBRs (Al-Halbouni et al., 2008; Drews et al., 2007; Kimura et al., 2009; Liang et al., 2007). The characteristics of SMPs in activated sludge systems depend on such factors as biomass concentration, organic loading rate and sludge retention time (SRT) (Barker and 
Stuckey, 1999), which affect membrane fouling in MBRs via changes in sludge characteristics. Many researchers pointed out the effect of these factors on membrane fouling in MBRs (Itonaga et al., 2004; Kimura et al., 2005b; Trussell et al., 2007). In addition, temperature affects the characteristics of SMPs as well, and therefore, can be also considered as an important factor affecting membrane fouling in MBRs. Rosenberger et al. (2006) reported that higher polysaccharide concentration in the mixed liquor suspension of MBRs during low-temperature periods corresponds to a higher fouling rate in MBRs. Similar results have been reported by Drews et al. (2007). However, physically irreversible fouling was not investigated in these studies. Jiang et al. (2005) reported that both physically reversible and irreversible fouling were significant in the MBR operated in low temperature. Although they proposed some key aspects that can be related to the development of physically irreversible fouling (e.g., sludge deflocculation, reduction in mass transfer rate, and slow biodegradation), they could not provide the data that can explain the proposed mechanisms. Current understanding of the seasonal variation in physically irreversible fouling remains insufficient.

The objective of this study was to investigate seasonal variation in membrane fouling in MBRs treating municipal wastewater. Membrane fouling is divided into physically reversible and irreversible fouling, and seasonal variation in those two types of membrane fouling was investigated. To evaluate the effect of operating conditions on seasonal variation of membrane fouling, two separate MBRs, with different SRTs were operated in parallel. We analyzed the dissolved organic matter in the mixed liquor suspension in the MBRs and the 
foulants extracted from the fouled membrane to investigate the effect of the changes in characteristics of organic matter on the development of physically irreversible fouling.

\section{Materials and methods}

\subsection{Continuous operation of pilot-scale MBRs}

Pilot-scale MBRs were operated continuously at the Soseigawa Wastewater Treatment Center, Sapporo, Japan. Two separate MBRs with different SRTs (MBR1 - short SRT and MBR2 long SRT) and fed with the same wastewater delivered from the inlet of the primary sedimentation basin of the facility were operated in parallel. The operating conditions for each MBR are summarized in Table 1. The MBRs had fixed operating conditions throughout one year, and the data obtained in about 200 days, including high- and low-temperature periods, was evaluated. Continuous operation was divided into three periods (Periods 1 3) depending on the temperature of the mixed liquor suspension. We investigated the development of membrane fouling and the characteristics of the foulant that caused physically irreversible fouling in each period. The sludge was allowed to acclimate to the operating conditions for more than 3 times the SRT prior to initiation of Period 1. Therefore, at the beginning of Period 1, a pseudo-steady state in each MBR can be assumed. At the beginning of Period 1, continuous monitoring was initiated after the chemical membrane cleaning of the membranes used during the acclimatization period. The chemical cleaning was effective for restoring membrane permeability and the filtration resistances of chemically cleaned membranes were almost equal to those of new membranes. The membrane modules 
were disassembled for extraction of foulant at the end of each period. Therefore, new membranes were installed at the beginning of Periods 2 and 3. Period 1 represents the period from day 0 to day 57 and this period corresponds to summer (high-temperature period). Period 2 was the period from day 58 to day 143. This period corresponds to the temperature-transition period of autumn. Period 3 represents the period from day 144 to the termination of continuous operation. This period corresponds to winter (low-temperature period). The mean temperatures of the mixed liquor suspension in Periods 1 and 3 were 22.6 and $10.1^{\circ} \mathrm{C}$, respectively. In Period 2, temperature gradually decreased from around 21 to $12^{\circ} \mathrm{C}$. The characteristics of the raw wastewater are listed in Table 2 .

Each MBR was equipped with a hollow-fiber microfiltration (MF) membrane module made of polyvinylidene fluoride (PVDF) with a total surface area of $1.3 \mathrm{~m}^{2}$ and nominal pore size of $0.4 \mu \mathrm{m}$ (Mitsubishi Rayon Engineering, Tokyo, Japan). Filtration was carried out with a constant flow rate using suction pumps. MBR1 had a reactor volume of $175 \mathrm{~L}$ and equipped with one membrane module that was operated with a membrane flux of $0.8 \mathrm{~m}^{3} / \mathrm{m}^{2} /$ day (33 $\mathrm{L} / \mathrm{m}^{2} / \mathrm{hr}$ ). MBR2 had a reactor volume of $350 \mathrm{~L}$ and two membrane modules were installed in MBR2. These two membrane modules were operated with different membrane fluxes. The data obtained for the membrane module operated with a membrane flux of $0.8 \mathrm{~m}^{3} / \mathrm{m}^{2} /$ day will be discussed in this paper. As a result, the two MBRs were operated with different HRT. However, the difference in HRT between the two MBRs was much smaller than that in SRT (Table 1). Therefore, we assumed that the difference between the two MBRs could mostly be attributed to the difference in SRT. Intermittent filtration (12 min filtration and 3 min pause) 
was also carried out. In each reactor, continuous aeration at $4.5 \mathrm{~m}^{3} / \mathrm{h}$ was applied. When membrane fouling became significant, the membrane modules were taken out from the reactor and were physically cleaned by spraying pressurized water on the membrane and surface wiping with a sponge. Based on visual inspection, all of the accumulated cake could be effectively removed from the membrane surface in every physical membrane cleaning. Repeated physical membrane cleaning was examined several times and did not show further reduction in resistance. Therefore, we assumed that the effectiveness of the physical membrane cleaning is reproducible. When membranes became severely fouled, it was difficult to maintain the constant flow rate. When the flow rate was not stabilized after implementation of physical cleaning, we judged that physical cleaning was not effective, and chemical membrane cleaning was done by submerging the membrane module in a solution of hydrochloric acid (pH 2) and sodium hypochlorite (500 ppm).

The degree of membrane fouling was evaluated from the membrane filtration resistance calculated by the following equation:

$J=\frac{\Delta P}{\mu R_{t}}=\frac{\Delta P}{\mu\left(R_{m}+R_{f}\right)}$

where $J$ is the membrane permeate flux $\left(\mathrm{m}^{3} / \mathrm{m}^{2} / \mathrm{s}\right), \Delta P$ is the transmembrane pressure (Pa), $\mu$ is the viscosity of permeate (Pa s), $R_{t}$ is the total filtration resistance $\left(\mathrm{m}^{-1}\right), R_{m}$ is the intrinsic membrane resistance $\left(\mathrm{m}^{-1}\right)$, and $R_{f}$ is the fouling resistance $\left(\mathrm{m}^{-1}\right)$. The development of physically irreversible fouling was evaluated from the filtration resistances recorded just after physical membrane cleaning. 


\subsection{Extraction of foulants from fouled membranes}

At the end of each period, foulants that caused physically irreversible fouling were extracted from the fouled membranes and analyzed. Membrane modules were taken out from the reactor and were disassembled. Membrane fibers were then manually wiped with a sponge to remove accumulated cake that accounted for physically reversible fouling. Foulant was extracted from the fouled membrane by soaking the membranes in a sodium hydroxide solution at $30^{\circ} \mathrm{C}$ for $24 \mathrm{~h}$. The $\mathrm{pH}$ of the extraction solution was set at 12 . After extraction, the total organic carbon (TOC) and excitation-emission matrices (EEM) fluorescence spectra were measured. The remaining solutions were subsequently processed with electric dialysis for desalination and lyophilized for Fourier transform infrared (FTIR) spectroscopy and solid-state cross-polarization magic-angle spinning carbon-13 nuclear magnetic resonance (CPMAS ${ }^{13} \mathrm{C}$ NMR) spectroscopy analyses.

\subsection{Analytical methods}

Concentrations of TOC and dissolved organic carbon (DOC) were determined using a TOC analyzer (TOC-V, Shimadzu, Kyoto, Japan). Samples for EEM spectra measurements, DOC, dissolved carbohydrates, and dissolved proteins concentrations were filtered with a polytetrafluoroethylene (PTFE) membrane (Advantec Toyo, Tokyo, Japan) with a pore size of $0.5 \mu \mathrm{m}$ prior to applying them to each analysis. Dissolved organic matter for FTIR spectra analysis was obtained by filtration using a mixed cellulose ether membrane (Advantec Toyo, Tokyo, Japan) with a pore size of $0.45 \mu \mathrm{m}$. Mixed liquor suspended solids (MLSS) concentration was measured in accordance with the Japanese standard methods (JSWA, 1984). 
The phenol-sulfuric acid method (Dubois et al., 1956) and the Lowry method (Lowry et al., 1951) were used for determining the concentration of carbohydrates and proteins, respectively. Glucose and bovine serum albumin (BSA) were used as standards for the measurements of carbohydrates and proteins, respectively. For FTIR analyses, $\mathrm{KBr}$ pellets containing $0.25 \%$ of the sample were prepared and examined in an FTIR spectrophotometer (FTIR-8400S, Shimadzu, Kyoto, Japan) at a resolution of $4 \mathrm{~cm}^{-1}$. A fluorescence spectrophotometer equipped with a 150-W ozone-free xenon lamp (RF-5300PC, Shimadzu, Kyoto, Japan) was used for measuring EEM spectra. In fluorescence measurements, the wavelength of both emission and excitation was varied stepwise by $5 \mathrm{~nm}$. Samples were diluted with Milli-Q water so that the optical density at $300 \mathrm{~nm}$ was $<0.02$ (Green and Bough, 1994). Prior to measuring fluorescence, the $\mathrm{pH}$ of the samples was adjusted to neutral. CPMAS ${ }^{13} \mathrm{C}$ NMR spectra were obtained in the same manner used in our previous study (Kimura et al., 2005b).

\section{Results and discussion}

\subsection{Continuous operation of pilot-scale MBRs}

Fig. 1 shows changes in total filtration resistance determined for each MBR. Data plotted in Fig. 1 were adjusted to $20^{\circ} \mathrm{C}$ equivalent values considering the influence of water viscosity on filtration resistance. The crosses in Fig. 1 represent the filtration resistance recorded just after physical membrane cleaning and the lines connecting those crosses (dashed lines in Fig. 1) show the development of physically irreversible fouling in each MBR. Seasonal variation 
in membrane fouling was clearly seen in MBR1 (short SRT). Membrane fouling in MBR1 was significant in the later part of Period 2 (after day 90) and in Period 3. Frequent physical membrane cleanings were, therefore, carried out in those periods. It was obvious that membrane fouling became more significant as the temperature in MBR1 decreased. These results were generally in accordance with previous reports (Drews et al., 2007; Rosenberger et al., 2006). Regarding to physically irreversible fouling, however, a different trend was observed. In MBR1, the development rate of physically irreversible fouling, which is indicated by the slope of the dashed line in Fig. 1, was lower in Period 3 than that in Periods 1 and 2. These results indicate that rapid development of membrane fouling in the low-temperature period in MBR1 was mainly attributed to physically reversible fouling. It can, therefore, be assumed that rapid development of membrane fouling in a low temperature could be mitigated by implementation of effective physical membrane cleaning in an operational scheme.

In MBR2 (long SRT), the development of membrane fouling was not significant except at the beginning of Period 3. The development rates of physically irreversible fouling in MBR2 were also lower than those in MBR1 and fairly constant throughout continuous operation. Based on these results it can be concluded that both types of membrane fouling (i.e., physically reversible and irreversible fouling) can be significantly mitigated using MBRs with long SRTs. In addition, seasonal variation in both types of membrane fouling became less significant when MBRs were operated with long SRTs. 
3.2 Relationship between concentrations of dissolved organic matter in mixed liquor and development rates in both types of membrane fouling

Table 3 lists the mean concentrations of DOC, dissolved carbohydrates, dissolved proteins in the mixed liquor suspension in each period. Since physically irreversible fouling is mainly caused by dissolved matter (Yamato et al., 2006), these parameters could be related to the development rates of physically irreversible fouling.

In MBR1, the concentrations of dissolved organic matter were higher in Period 3 than in Periods 1 and 2. As stated previously, the development rate of physically reversible fouling in MBR1 was higher in Period 3 than in Periods 1 and 2. Increases in concentrations of dissolved organic matter might affect the development rate of physically reversible fouling. In MBR1, a clear relationship between development rates of physically irreversible fouling and concentrations of dissolved organic matter could not be established. Physically irreversible fouling developed more rapidly in Periods 1 and 2 than in Period 3 in MBR1. However, the concentrations of DOC, dissolved carbohydrates, and dissolved proteins were highest in Period 3. For MBR2, changes in concentrations of dissolved organic matter were not significant throughout continuous operation. This corresponds to the changes in development rates in both types of membrane fouling in MBR2.

Rosenberger et al. (2006) pointed out the relationship between elevated polysaccharide concentration in low temperature and rapid development of membrane fouling. In their study, the SRT value was set to a similar value to that of MBR1 (8 days and 15 days). The results 
obtained in this study indicate that rapid development of membrane fouling as a consequence of accumulation of dissolved organic matter can only be observed in MBRs with short SRTs. Drews et al. (2008) reported that a relationship between the concentration of organic matter in mixed liquor and the fouling rate became less significant in MBRs with long SRTs. The importance of SRT on dissolved organic matter for membrane fouling was confirmed in this study. The results obtained in this study also indicate that changes in concentrations of dissolved organic matter can only be related to the development rates of physically reversible fouling, and those of physically irreversible fouling could not be explained by concentrations of dissolved organic matter. Therefore, the differences in the rates of physically irreversible fouling were thought to originate from the different characteristics of dissolved organic matter. These results are in accordance with the results reported by Kimura et al. (2009). The changes in characteristics of dissolved organic matter are discussed in the next section.

\subsection{Changes in characteristics of dissolved organic matter in mixed liquor suspension}

The ratio of carbohydrates to proteins $(\mathrm{C} / \mathrm{P})$ might provide some information on the characteristics of dissolved organic matter in the mixed liquor suspension of MBRs (Choi and Ng, 2008; Shin and Kang, 2003). In both MBRs, the C/P ratios for Periods 1 and 2 were similar, while that for Period 3 was apparently high. These results indicate that the characteristics of dissolved organic matter were different depending on the temperature period.

Fig. 2 shows FTIR spectra of dissolved organic matter. Measurements of FTIR spectra were 
carried out at least 3 times in each period and the results were similar in all of the measurements conducted in the same period. Representative spectra are shown in Fig. 2. The peak located near $1400 \mathrm{~cm}^{-1}$ is the discriminative peak for humic substances (Stevenson and Goh, 1971), and the peaks near $1100 \mathrm{~cm}^{-1}$ and $1620 \mathrm{~cm}^{-1}$ are attributed to polysaccharide-like substances (Barber et al., 2001) and aromatic $C=C$ (Chen et al., 2002), respectively. The sharp peak located on $1380 \mathrm{~cm}^{-1}$ is attributed to nitrate-nitrogen. For both MBRs, a shoulder peak located between 1400 and $1500 \mathrm{~cm}^{-1}$ was more significant in the FTIR spectra of the dissolved organic matter collected in Periods 2 and 3 compared with that in Period 1. A peak attributed to polysaccharide-like substances also became larger in Periods 2 and 3. The relative abundances of humic and polysaccharide-like substances were likely to increase as temperature during operation decreased.

Fig. 3 shows EEM fluorescence spectra measured for dissolved organic matter collected from each MBR in Periods 2 and 3. As with FTIR spectra analysis, representative EEM spectra are shown in Fig. 3 since similar results were obtained in all of the measurements conducted in the same period (4 times in Period 2 and 3 times in Period 3). EEM fluorescence spectra could not be measured in Period 1 due to mechanical failure of an analytical apparatus. In EEM fluorescence spectra, peaks located at Ex/Em $=275 \mathrm{~nm} / 350 \mathrm{~nm}$ and Ex/Em $=275$ $\mathrm{nm} / 425 \mathrm{~nm}$ can be attributed to protein-like and humic acid-like substances, respectively (Chen et al., 2003). The difference in the characteristics of dissolved organic matter in each temperature period can be seen in the EEM fluorescence spectra as well. For both MBRs, a peak that can be attributed to protein-like substances was apparent in the EEM fluorescence 
spectra obtained for dissolved organic matter collected in Period 2. Relative dominance of the peak of protein-like substances was higher in MBR1 indicating that dissolved organic matter in MBR1 had a more proteinaceous nature than that in MBR2. In the EEM fluorescence spectra measured in Period 3, a peak that can be attributed to humic acid-like substances was dominant. As mentioned above, FTIR spectra obtained for dissolved organic matter collected in each period demonstrated that the presences of polysaccharide-like and humic acid-like substances were more prominent in dissolved organic matter collected in the low-temperature period. The increase in the relative abundance of humic acid-like substances in the low-temperature period was confirmed in EEM fluorescence spectra analysis. The relative abundance of polysaccharide-like substances cannot be discussed because EEM fluorescence spectra analysis could not provide information on polysaccharide-like substances.

Based on the results of FTIR spectra and EEM fluorescence spectra analyses, it is obvious that the characteristics of the dissolved organic matter obtained in each period were different. Dissolved organic matter collected in the high-temperature period exhibited more proteinaceous characteristics than those in the low-temperature period. Drews et al. (2006) reported that specific consumption rate of proteins is higher than that of polysaccharides, indicating that proteins are easier to degrade by microorganisms than polysaccharide. Since the typical protein content of bacterial cells, which is thought to be one of the main origins of dissolved organic matter in a mixed liquor suspension, is around 50\% (Rittmann and McCarty, 2001), the organic matter in which protein is abundant can be thought to represent "flesh" organic matter. Dissolved organic matter collected in the low temperature period exhibited 
more polysaccharide-like or humic acid-like characteristics. Miyoshi et al. (2008) reported that these types of organic matter were abundant in the organic matter accumulated during aerobic digestion of activated sludge. Therefore, organic matter in which polysaccharide-like or humic acid-like substances are abundant can be regarded as representative of more “digested” organic matter. Although the concentration of dissolved organic matter was lower in the high-temperature period, the development rate of physically irreversible fouling in the high-temperature period was higher than that in the low-temperature period in this study. These results imply that flesh organic matter, which was abundant in the high-temperature period, has a higher potential for causing physically irreversible fouling.

\subsection{Characteristics of foulants extracted from fouled membranes}

Table 4 lists the amount of foulants extracted from the fouled membranes at the end of each period. The data listed in Table 4 are expressed as extracted TOC on the basis of a unit membrane surface area $\left(\mathrm{mg} / \mathrm{m}^{2}\right)$. As stated previously, foulant was extracted after wiping the membrane surface with a sponge. Therefore, the extracted foulant can be related to physically irreversible fouling developed in each period. The foulant could not be extracted or characterized during chemical membrane cleaning conducted in Periods 1 (on day 28) and 2 (on day 90) due to the limited number of membrane modules. In MBR1, due to the chemical membrane cleaning conducted during Periods 1 and 2, the time for the extraction test was longest in Period 3: 29 days for Period 1, 35 days for Period 2, and 57 days for Period 3. Since the membrane flux and operating cycle for intermittent filtration were fixed throughout continuous operation, the length of the operating period is directly related to the amount of 
filtered suspension. Since the concentrations of dissolved organic matter in MBR1 were highest in Period 3, it can be assumed that the amount of dissolved organic matter delivered to the membrane was largest in Period 3. However, in MBR1, the amount of extracted foulant was lowest in Period 3. It is obvious that a quantitative relationship between the amount of dissolved organic matter delivered to the membrane and the amount of extracted foulant could not be established. Therefore, the dissolved organic matter accumulated in the low-temperature period is thought to have a lower tendency of attaching to the membrane used in this study. In MBR2, the length of operation for each period was comparable, and the concentrations of dissolved organic matter were similar for all temperature periods. Therefore, it can be assumed that the amount of dissolved organic matter delivered to the membrane is similar for all temperature periods. In MBR2, the amounts of extracted foulant expressed as TOC were in the following order: Period $1>$ Period $2>$ Period 3. With MBR2, the dissolved organic matter accumulated in the low-temperature period was likely to have a lower tendency of attaching to the membrane as well. According to the data presented in Fig. 1 and Table 4, a quantitative relationship between the degree of physically irreversible fouling and the amount of extracted foulants was not established in MBR2. This result is in accordance with our previous studies (Kimura et al., 2005b; Yamato et al., 2006). The amount of extracted foulants cannot explain the degree of membrane fouling. Rather, property of foulants should be considered for better understanding of membrane fouling in MBRs.

FTIR spectra of the foulants extracted from the fouled membranes at the end of each period are presented in Fig. 4. The peaks near $1660 \mathrm{~cm}^{-1}$ and $1540 \mathrm{~cm}^{-1}$ are attributed to amide-I and 
-II bonds, respectively (Barber et al., 2001). Therefore, these peaks indicate the presence of protein-like substances in the foulants. As previously shown in Fig. 2, however, the peaks attributed to protein-like substance were not significant in the FTIR spectra obtained for dissolved organic matter. Appearance of the peaks of protein-like substance in the FTIR spectra for the foulants implies high affinity of protein-like substance to the membrane: protein-like substances could preferably attach to the membrane although the relative abundance of the protein-like substance was low compared with the other types of organic matter. For both MBRs, the peaks attributed to protein-like substance were dominant in the FTIR spectra obtained for the foulants extracted at the end of Period 1. The relative dominance of the peaks attributed to protein-like substances decreased and the peak attributed to polysaccharide-like substance became more significant as the temperature during operation decreased. In the FTIR spectra obtained for the foulants extracted from MBR2, the peak near $1400 \mathrm{~cm}^{-1}$, which is a discriminative peak for humic substances (Stevenson and Goh, 1971), also became significant as temperature during operation decreased. As shown in Fig. 2, peaks attributed to polysaccharide-like and humic substances became more significant in the FTIR spectra obtained from the dissolved organic matter collected in the low-temperature period. Those results correspond with the FTIR spectra measured for extracted foulants.

Fig. 5 shows EEM fluorescence spectra measured from the extracted foulants. In addition to the peaks found in the EEM measured for dissolved organic matter in the mixed liquor suspension, two peaks were found in the EEM measured from the extracted foulants. Those peaks were found at $\mathrm{Ex} / \mathrm{Em}=275 \mathrm{~nm} / 300 \mathrm{~nm}$ and $\mathrm{Ex} / \mathrm{Em}=350 \mathrm{~nm} / 425 \mathrm{~nm}$, which can be 
attributed to protein-like and humic acid-like substances, respectively (Chen et al., 2003). Similar to the FTIR spectra, the trends of variation in the shapes of EEM fluorescence spectra of the extracted foulants are similar to those of the dissolved organic matter in the mixed liquor suspension of MBRs. For both MBRs, a peak that can be attributed to protein-like substances was dominant in the EEM measured for the foulant extracted at the end of Period 1. In contrast, peaks that can be attributed to humic acid-like substances became dominant as temperature during operation decreased. This trend was more pronounced in MBR2. In FTIR spectra analysis of the extracted foulants, it was suggested that presence of humic acid-like substances was more prominent in the foulant extracted at the end of the low-temperature period. This is supported by the above discussion based on the results of EEM fluorescence spectra analysis of the extracted foulants. More pronounced proteinaceous characteristics for the foulants extracted at the end of the high-temperature period, indicated by FTIR spectra analysis of the extracted foulants, were also confirmed with EEM fluorescence spectra analysis.

CPMAS ${ }^{13} \mathrm{C}$ NMR spectra of the extracted foulants are presented in Fig. 6 . The shapes of the CPMAS ${ }^{13} \mathrm{C}$ NMR spectra of the extracted foulants were different depending on the operating periods. Taking the results of FTIR and EEM analyses that indicated difference in characteristics of extracted foulants into account, it can be concluded that the characteristics of foulants differed depending on operating period even though the operating conditions for both MBRs were fixed. For both MBRs, the peak found near $140 \mathrm{ppm}$, which is attributed to aromatic carbon (Barber et al., 2001), was more pronounced in the CPMAS ${ }^{13} \mathrm{C}$ NMR spectra 
measured for the foulant extracted at the end of the low-temperature period. In addition, the peak found at 165 ppm, which can be attributed to aromatic carboxyl groups (Leenheer et al., 1995), can only be clearly observed in the CPMAS ${ }^{13} \mathrm{C}$ NMR spectra of the foulant extracted from MBR2 at the end of Period 3. It was likely that the presence of aromatic substances (i.e., humic substance) was more prominent in the low-temperature period. As stated previously, FTIR and EEM fluorescence spectra of the extracted foulants also indicated that the relative abundance of humic substances was higher in the foulant extracted at the end of the low-temperature period. The results of CPMAS ${ }^{13} \mathrm{C}$ NMR spectra correspond to the results of FTIR spectra and EEM fluorescence spectra analyses.

On the basis of the arguments mentioned above, it can be concluded that changes in the characteristics of dissolved organic matter in the mixed liquor suspension are similar to changes in the characteristics of foulants that caused physically irreversible fouling. Since the development rates of physically irreversible fouling could not be explained by the quantity of organic matter delivered to the membrane, it is thought that quality rather than quantity of organic matter is important for the development of physically irreversible fouling. As mentioned above, the dissolved organic matter accumulated in the mixed liquor suspension in the high-temperature period is likely to have a higher potential for causing physically irreversible fouling than that in the low-temperature period. Taking into consideration the results of FTIR spectra and EEM fluorescence spectra analyses, indicating the organic matter in the high-temperature period showed more proteinaceous characteristics, it can be suggested that organic matter, in which protein-like substances are abundant, would cause 
severe physically irreversible fouling. Further study regarding the relationship between the characteristics of organic matter and its potential for causing physically irreversible fouling is needed.

\section{Conclusions}

We investigated seasonal variation of membrane fouling in MBRs treating municipal wastewater. In MBR1 (short SRT), development rates of membrane fouling differed depending on the operational period. With MBR2 (long SRT), seasonal variation of membrane fouling was not observed. Physically reversible fouling in the MBR1 became significant in the low-temperature period, while the development rate of physically irreversible fouling was higher in the high-temperature period. Rapid development of physically reversible fouling in the low-temperature period in the MBR1 was likely caused by accumulation of dissolved organic matter in the mixed liquor suspension. In contrast, the development rates of physically irreversible fouling could not be explained with concentrations of dissolved organic matter in the mixed liquor suspension. The difference in the development rate of physically irreversible fouling could be related to the difference in the characteristics of dissolved organic matter in the mixed liquor suspension. Dissolved organic matter collected in the high-temperature period showed more pronounced proteinaceous characteristics while polysaccharide-like or humic acid-like substances were abundant in the dissolved organic matter collected in the low-temperature period. A similar trend was found in the variation in characteristics of foulants that caused physically 
irreversible fouling during continuous operation indicating, that changes in the characteristics of dissolved organic matter in the mixed liquor suspension affected the characteristics of the foulants. Since the organic matter formed in the high-temperature period may have a higher potential for causing physically irreversible fouling, it is thought that organic matter, in which protein-like substances are abundant, causes severe physically irreversible fouling.

\section{Acknowledgements}

This work was supported by the Research Fellowship of the Japan Society for the Promotion of Sciences for Young Scientists. 


\section{References}

Al-Halbouni, D., Traber, J., Lyko, S., Wintgens, T., Melin, T., Tacke, D., Janot, A., Dott, W., Hollender, J., 2008. Correlation of EPS content in activated sludge at different sludge retention times with membrane fouling phenomena. Water Res. 42, 1475-1488.

Barber, L. B., Leenheer, J. A., Noyes, T. I., Stiles, E. A., 2001. Nature and transformation of dissolved organic matter in treatment wetlands. Environ. Sci. Technol. 35, 4805-4816.

Barker, D. J., Stuckey, D. C., 1999. A review of soluble microbial products (SMP) in wastewater treatment systems. Water Res. 33, 3063-3082.

Chang, I. -S., Le-Clech, P., Jefferson, B., Judd, S., 2002. Membrane fouling in membrane bioreactors for wastewater treatment. J. Environ. Eng. 128, 1018-1029.

Chen, J., Gu, B., Leboeuf, E. J., Pan, H., Dai, S., 2002. Spectroscopic characterization of the structural and functional properties of natural organic matter fractions. Chemosphere 48, 59-68.

Chen, W., Westerhoff, P., Leenheer, J. A., Booksh, K., 2003. Fluorescence excitation-emission matrix regional integration to quantify spectra for dissolved organic matter. Environ. Sci. Tech. 37, 5701-5710. 
Choi, J. H., Ng, H. Y., 2008. Effect of membrane type and material on performance of a submerged membrane bioreactor. Chemosphere 71, 853-859.

Drews, A., Vocks, M., Iversen, V., Lesjean, B., Kraume, M., 2006. Influence of unsteady membrane bioreactor operation on EPS formation and filtration resistance. Desalination 192, $1-9$.

Drews, A., Mante, J., Iversen, V. Vocks, M., Lesjean B., 2007. Impact of ambient conditions on SMP elimination and rejection in MBRs. Water Res. 41, 3850-3858.

Drews, A., Vocks, M., Bracklow, U., Iversen, V., Kraume, M., 2008. Does fouling in MBRs depend on SMP? Desalination 231, 141-149.

Dubois, M., Gilles, K. A., Hamilton, J. K., Rebers, P. A., Smith, F., 1956. Colorimetric determination of sugars and related substances. Anal. Chem. 28, 350-356.

Green, S. A., Blough, N. V., 1994. Optical absorption and fluorescence properties of chromophoric dissolved organic matter in natural waters. Limnol. Oceanogr. 39 (8), 1903-1916.

Itonaga, T., Kimura, K., Watanabe, Y., 2004. Influence of suspension viscosity and colloidal 
particles on permeability of membrane used in membrane bioreactor (MBR). Water Sci. Technol. 50 (12), 301-309.

Japan Sewage Works Association, Standard methods for the examination of wastewater, Tokyo, 1984 (in Japanese).

Jiang, T., Kennedy, M. D., Guinzbourg, B. F., Vanrolleghem, P. A., Schippers, J. C., 2005. Optimising the operation of a MBR pilot plant by quantitative analysis of the membrane fouling mechanism. Water Sci. Technol. 51 (6-7), 19-25.

Kimura, K., Hara, H., Watanabe, Y., 2005a. Removal of pharmaceutical compounds by submerged membrane bioreactors (MBRs). Desalination 178, 135-140.

Kimura, K., Yamato, N., Yamamura, H., Watanabe, Y., 2005b. Membrane fouling in pilot-scale mambrane bioreactors (MBRs) treating municipal wastewater. Environ. Sci. Technol. 39, 6293-6299.

Kimura, K., Nishisako, R., Miyoshi, T., Watanabe, Y., 2008. Baffled membrane bioreactor (BMBR) for efficient nutrient removal from municipal wastewater. Water Res. 42, 625-632.

Kimura, K., Naruse, T., Watanabe, Y., 2009. Changes in characteristics of soluble microbial products in membrane bioreactors associated with different solid retention times: Relation to 
membrane fouling. Water Res. 43, 1033-1039.

Leenheer, J. A., Wershaw, R. L., Reddy, M. M., 1995. Strong-acid, carboxyl-group in fulvic acid from the Suwannee River, Georgia. 1. Minor structures. Environ. Sci. Technol. 29, 393-398.

Liang, S., Liu, C., Song, L., 2007. Soluble microbial products in membrane bioreactor operation: behaviors, characteristics, and fouling potential. Water Res. 41, 95-101.

Lowry, O. H., Rosebrough, N. J., Farr, A. L., Randall, R. J., 1951. Protein measurement with the Folin phenol reagent. J. Biol. Chem. 193, 265-275.

Miyoshi, T., Naruse, T., Ogyu, R., Kimura, K., Watanabe, Y., 2006. Origin of foulants in membrane bioreactors (MBRs) treating municipal wastewater. J. Japan Soc. Water Environ. 31, 541-548 (in Japanese).

Rittmann, B. E., Mccarty, P. L., 2001. Environmental Biotechnology: Principles and Applications. McGraw Hill, Boston.

Rosenberger, S., Laabs, C., Lesjean, B., Gnirss, R., Amy, G., Jekel, M., Schrotter, J. -C., 2006. Impact of colloidal and soluble organic material on membrane performance in membrane bioreactors for municipal wastewater treatment. Water Res. 40, 710-720. 
Shin, H.-S., Kang, S.-T, 2003. Characteristics and the fates of soluble microbial products in ceramic membrane bioreactor at various sludge retention times. Water Res. 37, 121-127.

Stephenson, T., Judd, S., Jefferson, B., Brindle, K., 2000. Membrane bioreactors for wastewater treatment. IWA publishing, London.

Stevenson, F. J., Goh, K. M., 1971. Infrared spectra of humic acids and related substances. Geochim. Cosmochim. Acta 35, 471-488.

Trussell, R. S., Merlo, R. P., Hermanowics, S. W., Jenkins, D., 2007. Influence of mixed liquor properties and aeration intensity on membrane fouling in a submerged membrane bioreactor at high mixed liquor suspended solid concentrations. Water Res. 41, 947-958.

Yamamoto, K., Hiasa, M., Mahood, T., Matsuo, T., 1989. Direct solid-liquid separation using hollow fiber membrane in an activated sludge aeration tank. Water Sci. Technol. 21 (4-5), 43-54.

Yamato, N., Kimura, K., Miyoshi, T., Watanabe, Y., 2006. Difference in membrane fouling in membrane bioreactors (MBRs) caused by membrane polymer materials. J. Membr. Sci. 280, 911-919. 
Table 1 Operating conditions of each MBR.

\begin{tabular}{llcc}
\hline & & MBR1 & MBR2 \\
\hline Membrane flux & $\left(\mathrm{m}^{3} / \mathrm{m}^{2} /\right.$ day $)$ & & 0.8 \\
& $\left(\mathrm{~L} / \mathrm{m}^{2} / \mathrm{hr}\right)$ & \multicolumn{2}{c}{33} \\
HRT & $(\mathrm{h})$ & 6 & 7 \\
SRT & (day) & 13 & 50 \\
MLSS $^{a}$ & (g/L) & $4.2(3.4-5.4)$ & $10.9(8.6-13.4)$ \\
\hline
\end{tabular}

- Values in parenthesis are minimum and maximum values. 
Table 2 Characteristics of raw wastewater.

\begin{tabular}{|c|c|c|c|c|c|}
\hline & $\mathrm{TOC}(\mathrm{mg} / \mathrm{L})$ & $\mathrm{DOC}(\mathrm{mg} / \mathrm{L})$ & $\mathrm{NH}_{4^{+}}-\mathrm{N}(\mathrm{mg} / \mathrm{L})$ & $\mathrm{T}-\mathrm{P}(\mathrm{mg} / \mathrm{L})$ & Temperature $\left({ }^{\circ} \mathrm{C}\right)$ \\
\hline Period $1^{a}$ & $37.2(9.6)$ & $22.9(6.4)$ & $17.9(4.1)$ & $2.4(0.6)$ & $21.5(1.1)$ \\
\hline Period $2^{\circ}$ & $47.3(22.7)$ & $27.8(17.0)$ & 13.8 & $2.8(1.1)$ & $17.7(2.7)$ \\
\hline Period $3^{c}$ & $45.0(22.9)$ & 23.6 (19.2) & $13.0(2.0)$ & $2.1(0.7)$ & $12.7(1.3)$ \\
\hline
\end{tabular}

Values in parenthesis are standard deviation. $n=10 .{ }^{*} n=16 .{ }^{*} n=14$. 
Table 3 Mean concentrations of DOC, dissolved carbohydrates, and dissolved proteins in each operating period.

\begin{tabular}{|c|c|c|c|c|c|c|}
\hline & \multicolumn{3}{|c|}{ MBR1 } & \multicolumn{3}{|c|}{ MBR2 } \\
\hline & $\begin{array}{c}\text { DOC } \\
(\mathrm{mg} / \mathrm{L})\end{array}$ & $\begin{array}{c}\text { Carbohydrate } \\
\text { (mg/L) }\end{array}$ & $\begin{array}{l}\text { Protein } \\
\text { (mg/L) }\end{array}$ & $\begin{array}{c}\text { DOC } \\
(\mathrm{mg} / \mathrm{L})\end{array}$ & $\begin{array}{c}\text { Carbohydrate } \\
(\mathrm{mg} / \mathrm{L})\end{array}$ & $\begin{array}{l}\text { Protein } \\
\text { (mg/L) }\end{array}$ \\
\hline Period $1^{a}$ & $9.5(4.0)$ & $24.1(13.5)$ & $7.3(1.6)$ & $5.6(1.2)$ & $8.5(4.6)$ & $5.4(0.8)$ \\
\hline Period $2^{b}$ & $14.8(7.5)$ & $25.4(15.0)$ & $9.9(3.7)$ & $7.8(3.6)$ & $8.3(5.0)$ & $5.5(1.6)$ \\
\hline Period $3^{c}$ & $22.5(7.3)$ & $49.1(13.1)$ & $11.3(2.1)$ & $8.0(3.2)$ & $14.2(7.1)$ & $7.1(1.8)$ \\
\hline
\end{tabular}

Values in parenthesis are standard deviation. ${ }^{a} n=10 .{ }^{b} n=18 .{ }^{c} n=14$. 
Table 4 Amount of TOC extracted from fouled membrane at termination of each operating period. Units are $\mathrm{mg} / \mathrm{m}^{2}$.

\begin{tabular}{lccc}
\hline & Period 1 & Period 2 & Period 3 \\
\hline MBR1 & 168.3 & 249.7 & 143.0 \\
MBR2 & 272.6 & 185.2 & 66.3 \\
\hline
\end{tabular}




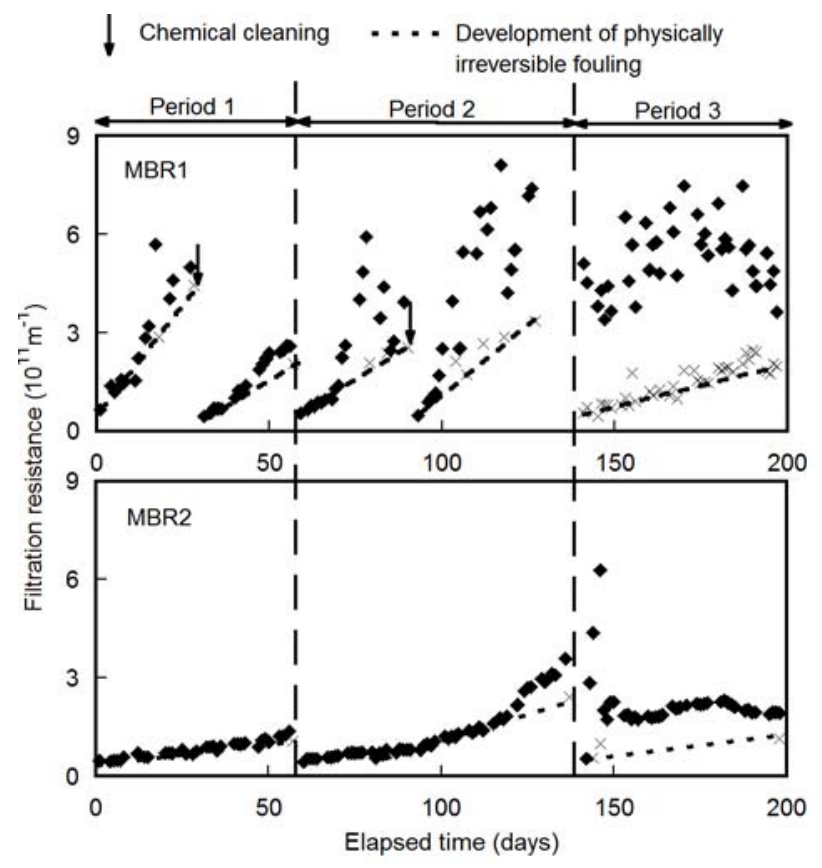

Fig. 1 Changes in total filtration resistances during continuous operation. Crosses represent filtration resistances recorded just after physical membrane cleaning. 

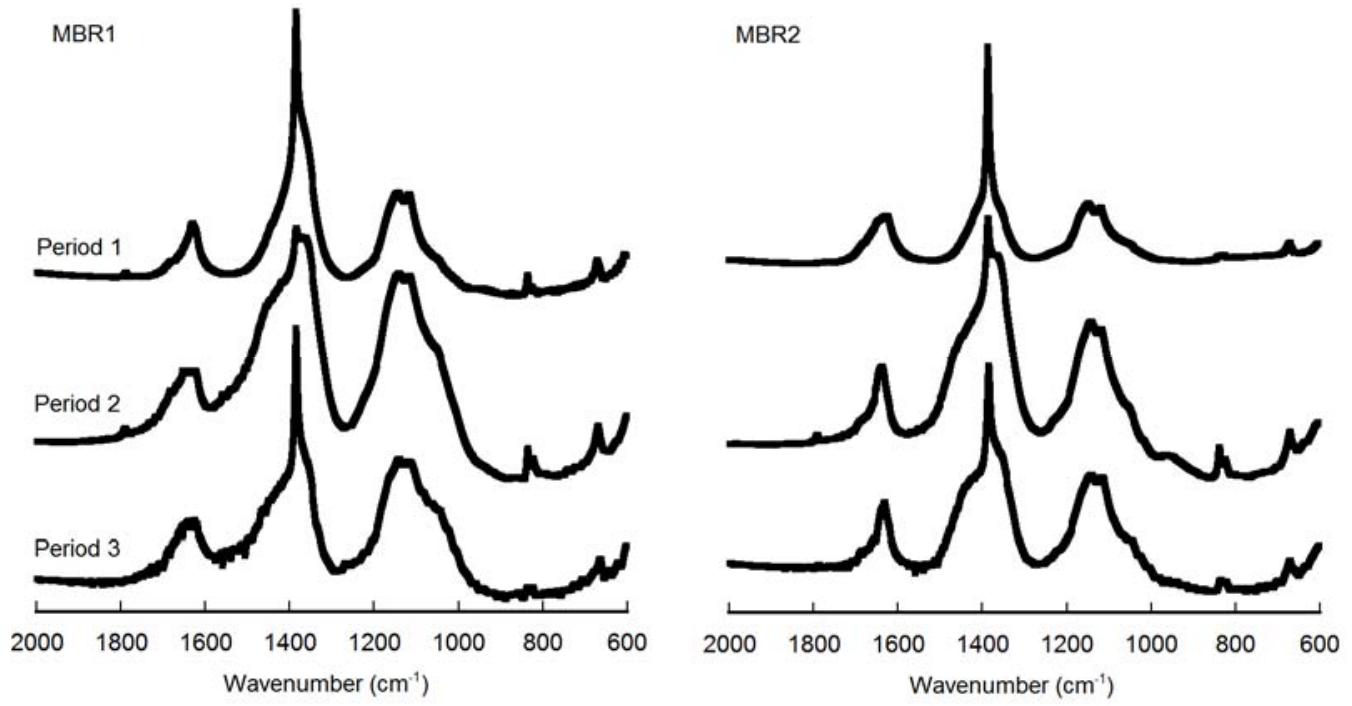

Fig. 2 FTIR spectra of dissolved organic matter in mixed liquor suspension. 

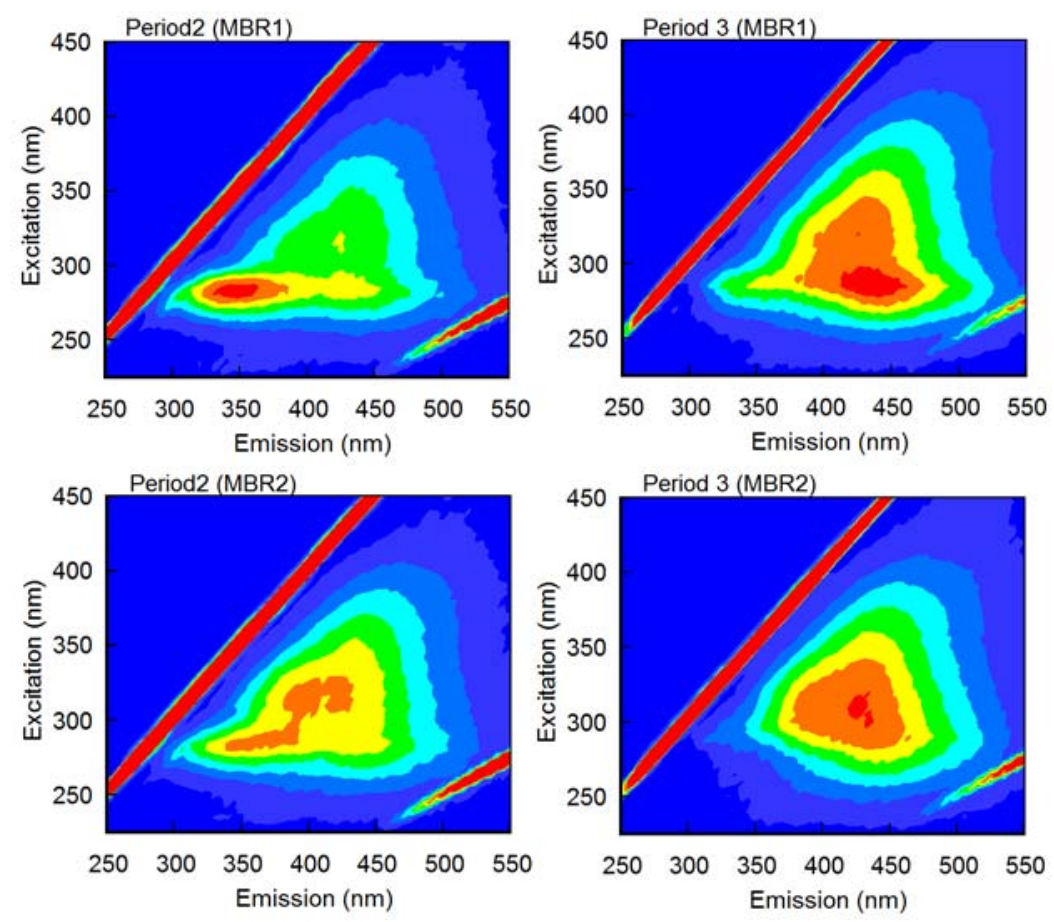

Fig. 3 Fluorescence EEMs of dissolved organic matter in mixed liquor suspension. 

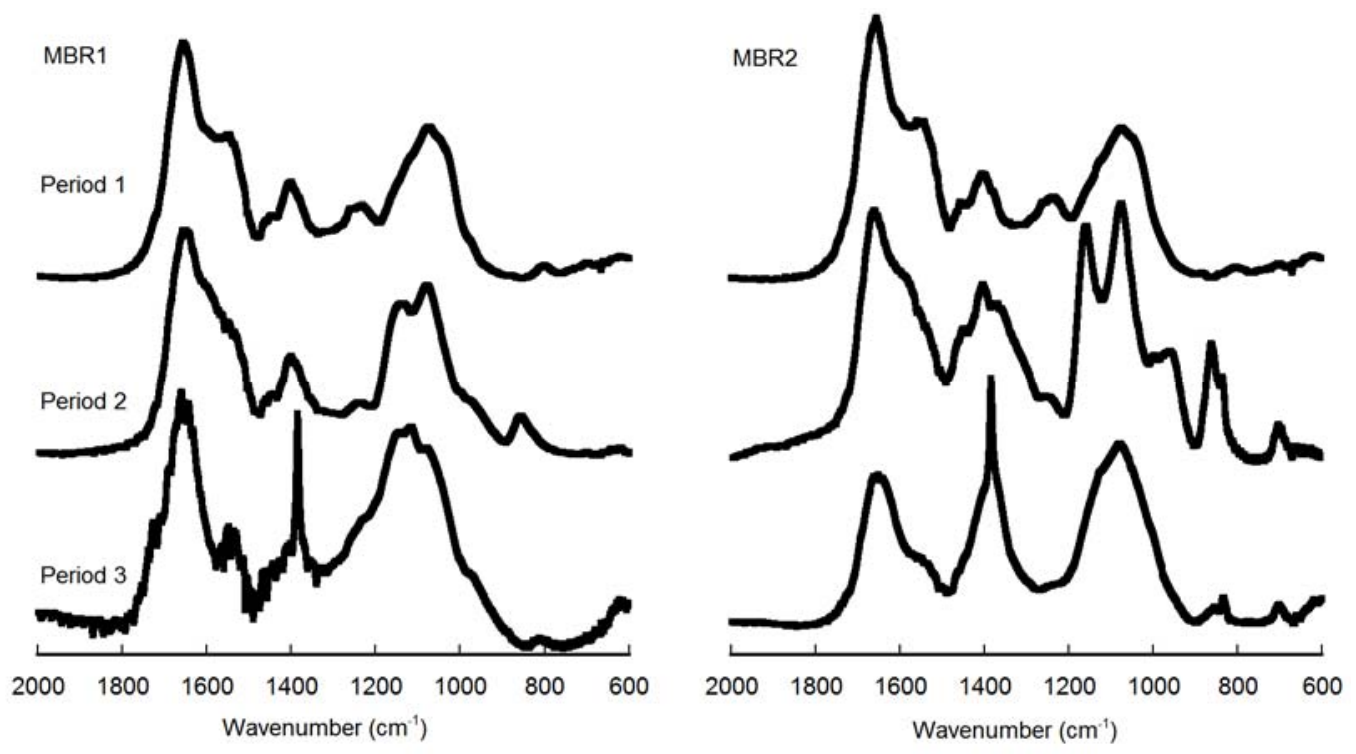

Fig. 4 FTIR spectra of foulants extracted from fouled membrane at termination of each operating period. 

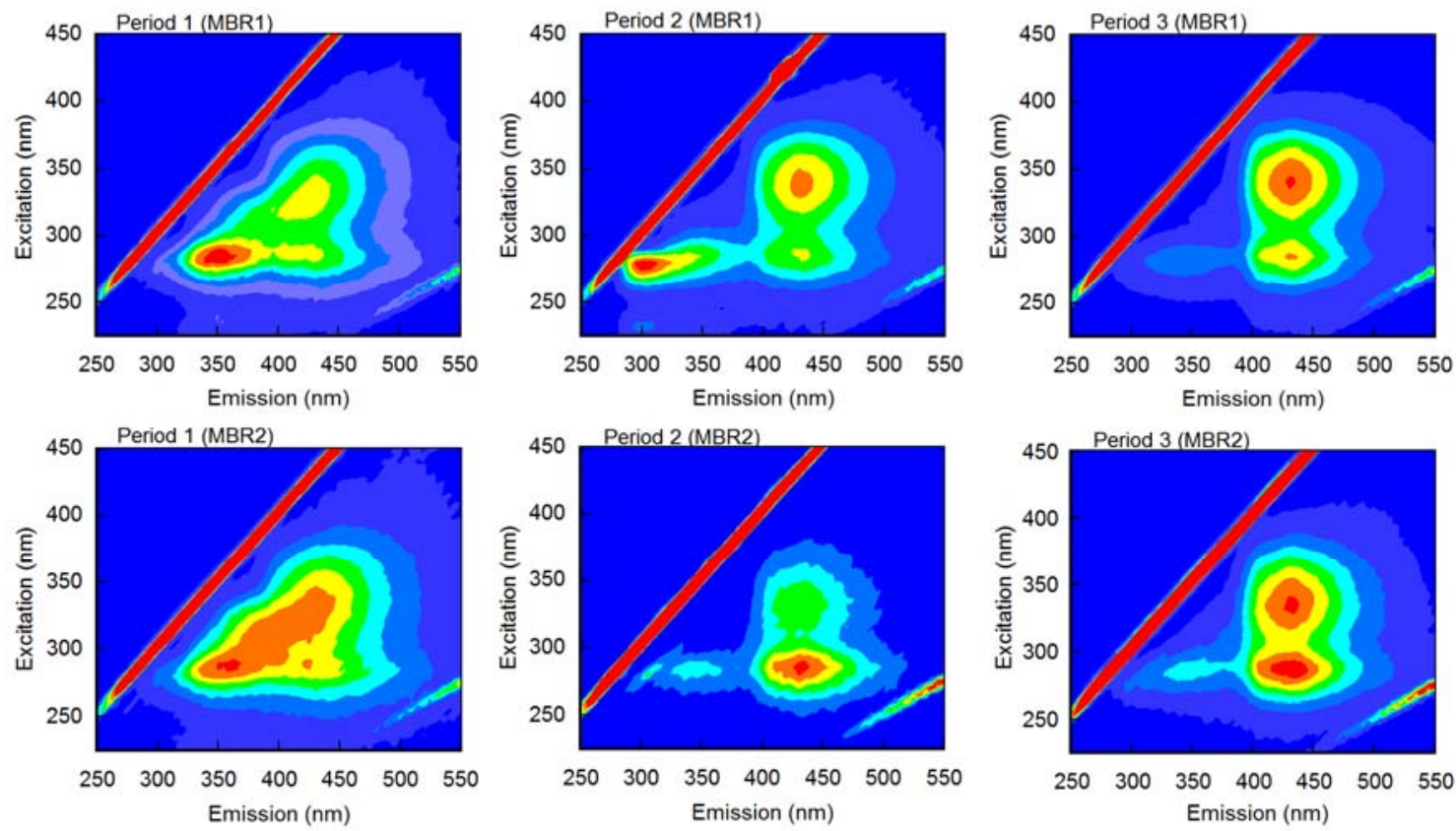

Fig. 5 Fluorescence EEMs of foulants extracted from fouled membrane at termination of each operating period. 

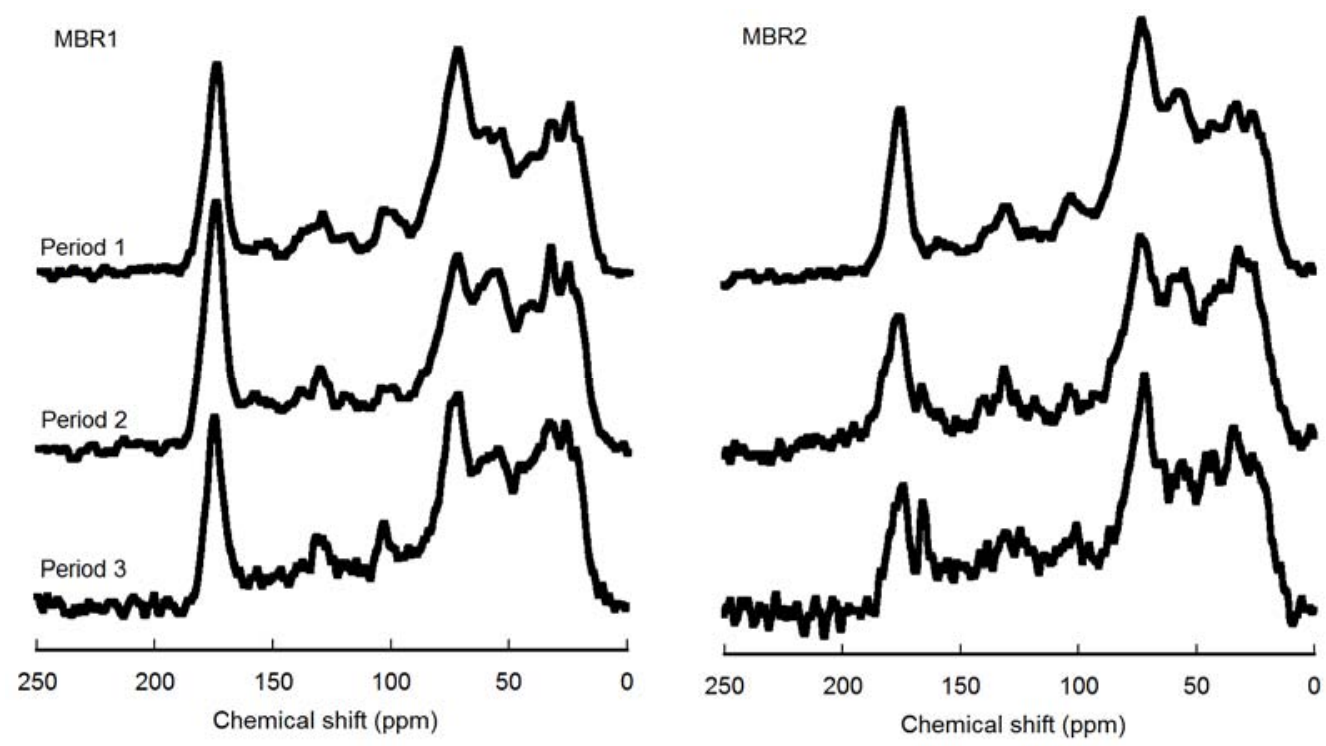

Fig. 6 CPMAS ${ }^{13} \mathrm{C}$ NMR spectra of foulants extracted from fouled membrane at termination of each operating period. 